or more may exist in the temperature readings. The absence of any correction on this account vitiates many of the published data. Specific instances will be noted in later papers dealing with vapor pressures.

[Communication from the Laboratories of General and Physical Chemistry
of the University of Chicago.]

STUDIES IN VAPOR PRESSURE: II. A SIMPLE DYNAMIC METHOD, APPLICABLE TO BOTH SOLIDS AND LIQUIDS, FOR DETERMINING VAPOR PRESSURES, AND ALSO BOILING POINTS AT STANDARD PRESSURES.

By ALEXander SMith and Alan W. C MeNzies.

Received June II, Igro.

The principle of the submerged bulblet method of determining boiling points, described in the preceding paper, may be adapted to the measurement of vapor pressures. The necessary apparatus may be set up from materials found in any laboratory, and a series of measurements of considerable accuracy may be made, all with the expenditure of very little time.

The Apparatus.-The bulblet, with attached capillary tube not less than I mm. in diameter, is charged with a small amount (about o. I g.) of the solid or liquid substance, and is attached to the thermometer by means of thread or asbestos cord, just as for the boiling-point determination. Instead, however, of being then immersed directly in the open bath, it is enclosed in a test tube (see figure). The L-shaped tube leads to the manometer, connections with the atmosphere and with a pump being provided by means of T-tubes. A large bottle between the pump and manometer is useful for regulating the pressure. Stopcocks on the tube leading to the pump and on that opening to the air permit the pressure to be lowered or raised at will. For pressures below that of the atmosphere, a water-pump, and for pressures above that of the atmosphere a small

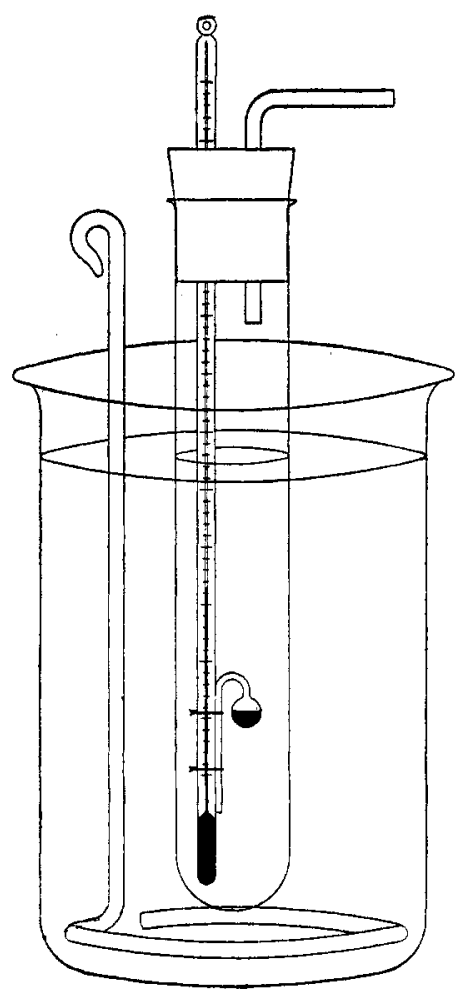
compression pump (e.g., a bicycle pump) may be used. With only a 
rubber stopper closing the test tube, the pressure cannot be carried far above that of the atmosphere. But this apparatus will serve well when direct observation of the boiling point at standard pressure $(760 \mathrm{~mm}$.) is desired.

The test tube contains the same liquid as the surrounding bath. What was said in the first paper in regard to suitable bath liquids (p. 899), and in regard to the choice of thermometers (p. 902) applies here. The bath may be stirred by hand.

The Manipulation.--It will be sufficient to describe the mode of operation when pressures below that of the atmosphere are being observed. After the temperature has become constant at the desired point, and time has been allowed for equalization of the temperatures within and without the test tube, the pressure is reduced by cautiously opening the stopcock on the tube leading to the pump. When the pressure has fallen to, or just below, the vapor pressure of the solid or liquid, a continuous stream of bubbles issues from the capillary. In a few moments, the vapor of the substance has displaced the air in the bulb, and usually also all the oxygen, nitrogen, or moisture dissolved in the substance, or adhering to the substance or the glass. The stop-cock on the tube leading to the pump is now closed, and that admitting air is slightly opened. The pressure is allowed slowly to rise until the stream of bubbles ceases. Use of the stop-cock alone does not permit of fine adjustment. Admission of air, a very little at a time, is best effected by grasping and closing the rubber tube at two places with the fingers. The volume of air in the enclosed section of the tubing bears only a small ratio to the total volume of the apparatus, including the bottle. By opening and closing the two constrictions alternately, first that next to the apparatus, then that nearer to the end which is open to the atmosphere, air is admitted in minute amounts at a time, and the pressure is raised very gradually. When the stream of bubbles suddenly ceases, the pressure of the air in the apparatus is equal to that of the vapor. The pressure at this moment is read on the manometer. This method applies when the substance and bath liquid are mutually insoluble. When they are mutually soluble, the bath liquid is allowed to ascend to a predetermined point, 5-10 $\mathrm{mm}$. from the mouth of the capillary, just as in the boiling-point determination (p. 9oo).

To make sure that the dissolved or adhering gases and moisture are all expelled, the pressure is lowered, and the boiling out and subsequent operations are repeated. If consecutive measurements do not finally give constant values at the same temperature, the substance is impure, either because of original impurity or of decomposition during the heating. When a satisfactory reading has been obtained, the temperature is raised $5^{\circ}$ or $10^{\circ}$ and the same operations are carried out at the new 
temperature. If an open manometer is used, the barometric height (reduced to mercury at $o^{\circ}$ ) is taken also, and the reading of the manometer (likewise reduced to $o^{\circ}$ ) is subtracted from it.

A correction for the pressure, due to the depth from the surface of the bath down to the mouth of the capillary, or to the point to which the liquid ascends, is required. The details of this correction are identical with those described in the paper on boiling points (p. 90I).

Sample Determination: Water.-To illustrate the adaptability of this form of the submerged bulblet method to securing quickly and easily a series of measurements of moderate accuracy, the results with water may be given. The test tube and bath were filled with mineral oil. Elaborate precautions to insure accuracy were purposely avoided. The manometer consisted of a piece of glass tubing fastened rigidly to an ordinary wooden meter scale. It stood in a vessel of mercury. Correction was made for capillarity in the manometer $(+\mathrm{I} .7 \mathrm{~mm}$ ), and the readings of the manometer and barometer were reduced to mercury at $0^{\circ}$. The correction for the immersed depth of the bulblet was made. One of a set of short Anschütz thermometers graduated in fifths of a degree was used, and the thread was completely immersed. Comparison with a standard thermofneter showed no errors over $0.05^{\circ}$, and the readings were therefore assumed correct. The following were the observed readings, after correction:

$\begin{array}{cccccccc}\text { Temp. } & \text { S.p. } & \text { V.p. } & \text { Diff. } & \text { V.p. } & \text { V.p. } & \text { Diff. } \\ 49.0 & 88.0 & {[87.8]} & +0.2 & 80.0 & 355.4 & 355.1 & +0.3 \\ 60.7 & 155.3 & \text { I54.I } & +\mathrm{I} .2 & 85.5 & 44 \mathrm{I} .5 & 442.2 & -0.7 \\ 67.8 & 213.8 & 212.2 & +1.6 & 90.0 & 526.5 & 525.8 & +0.7 \\ 73.6 & 273.5 & 272.5 & +1.0 & 95.3 & 640.5 & 641.1 & -0.6\end{array}$

The columns $\mathrm{H} \& \mathrm{H}$ contains the values published by Holborn and Henning, ${ }^{1}$ which are the most trustworthy available. The algebraic sum of the differences divided by the number of observations gives the divergence of the curve as a whole from that of $\mathrm{H} \mathrm{\& H}$. This divergence is $0.46 \mathrm{~mm}$, and the corresponding divergence of the temperature is $0.07^{\circ}$.

This arrangement was used successfully in preliminary measurements of the vapor pressures of mercury and of non-fusing solids like the mercurous halides at $280-370^{\circ}$.

Three Additional Sources of Error, and the Corrections Therefor.-The irregularity of the individual observations cited above is due to the crudeness of the manometer, chosen intentionally to avoid the use of any special apparatus. Aside from this, however, there are three other sources of error for which, if desired, correction may be made.

${ }^{1}$ Ann. Physik, [4] 26, 882 (rgo8). 
One of them is the error due to neglecting the pressure caused by capillary ascension of the bath liquid in a tube $\mathrm{Imm}$. in diameter. As we have shown, ${ }^{1}$ this involves an error of only about $1 \mathrm{~mm}$. of mercury pressure, or usually about $0.04^{\circ}$ in temperature. In the case of the paraffin oil used in the foregoing determinations, this error was only $0.5-0.6 \mathrm{~mm}$. Unless, therefore, the temperature is being read with unusual precautions, this correction may be ignored.

The second source of error lies in the fact to which attention is called in a separate communication, ${ }^{2}$ namely, that a thermometer bulb placed in a partial vacuum undergoes dilatation and gives low readings.

The amounts of these two corrections, and the effect of taking account of them, is shown with the same data in the following table:

\begin{tabular}{|c|c|c|c|c|c|c|c|}
\hline Temp. & $\begin{array}{l}\text { V.p. } \\
S \text { and } M .\end{array}$ & $\begin{array}{l}\text { Temp. cort. } \\
\text { for } \\
\text { dilatation. }\end{array}$ & $\begin{array}{l}\text { V.p. } \\
\text { change } \\
\text { per To. }\end{array}$ & $\begin{array}{l}\text { Corr. for } \\
\text { dilatation } \\
\text { in mm. }\end{array}$ & $\begin{array}{l}\text { Corr. for } \\
\text { capil. } \\
\text { in mmi. }\end{array}$ & $\begin{array}{l}S \text { and } M \\
\text { corr. }\end{array}$ & $\begin{array}{c}\text { Diff. from } \\
\text { H \& } \mathrm{H} .\end{array}$ \\
\hline $49.0^{\circ}$ & 88.0 & $0.13^{\circ}$ & $4 \cdot 5$ & -0.6 & +0.6 & 88.0 & +0.2 \\
\hline 60.7 & $155 \cdot 3$ & O.II & $7 \cdot 1$ & -0.8 & +0.6 & I $55 \cdot I$ & +1.0 \\
\hline 67.8 & 213.8 & 0.10 & 9.2 & -0.9 & +0.6 & $213 \cdot 5$ & +1.3 \\
\hline 73.6 & $273 \cdot 5$ & 0.09 & II .5 & -1.0 & +0.6 & $273 \cdot 1$ & +0.6 \\
\hline 80.0 & $355 \cdot 4$ & 0.08 & 14.6 & -1.2 & +0.5 & $354 \cdot 7$ & -0.4 \\
\hline $85 \cdot 5$ & $44 I \cdot 5$ & 0.06 & I $7 \cdot 3$ & -1.0 & +0.5 & $44 \mathrm{I} \cdot \mathrm{O}$ & -1.2 \\
\hline 90.0 & 526.5 & 0.04 & 20.0 & -0.8 & +0.5 & 526.2 & +0.4 \\
\hline $95 \cdot 3$ & 640.5 & 0.02 & $23 \cdot 4$ & -0.5 & +0.5 & 640.5 & -0.6 \\
\hline
\end{tabular}

By these corrections, the divergence from the standard values is reduced from $0.46 \mathrm{~mm}$. to $0.16 \mathrm{~mm}$, or, in temperature, from $0.07^{\circ}$ to $0.03^{\circ}$.

It will be seen that these two corrections work in opposite directions. On this account, when the present apparatus is used for securing a series of approximate vapor pressures, and for the applications to be mentioned presently, they may be neglected. When accurate vapor pressure measurements are required by a dynamic method, a modified, less simple form of the apparatus, to be described in a later paper, may be employed with advantage. In this apparatus, one of these corrections (that for dilatation) disappears, and the other is therefore to be taken into account.

The pressures may be still further corrected for the value of the gravity constant at the place of observation. In this laboratory the correction is $-0.25 \mathrm{~mm}$. per $760 \mathrm{~mm}$. This correction, if applied, reduces the average divergence of the curve of pressures observed from the standard curve to $0.06 \mathrm{~mm}$., or about $0.01^{\circ}$. This final result shows that by the method results of remarkable accuracy are obtainable.

Application to the Determination of Boiling Points of $760 \mathrm{~mm}$., and under Reduced Pressure.-The present, almost universal custom of pub-

${ }^{1}$ See first paper, This Journal, 32, 902.

' See preceding paper, ThIs Journal, 32, 906, 
lishing boiling points at whatever atmospheric pressure happens to exist at the time, aggravated in the majority of cases by omission to state what that pressure was, raises some question as to the carefulness of the whole investigation, and, besides, tends to defeat the purpose for which ostensibly such data are given, namely the identification of substances. Thus, even when the barometric height is only $16 \mathrm{~mm}$. distant from $760 \mathrm{~mm}$., the boiling point of alcohol is $0.5^{\circ}$ in error and that of naphthalene no less than $I^{\circ}$. It is extremely desirable that uniformity should be observed, and that all boiling points of stable substances should be ascertained at the normal pressure of $760 \mathrm{~mm}$., and published in that form. The submerged bulblet method just described renders this operation so easy that the added value of the data is worth far more than the little extra trouble involved.

When the substance is unstable at its boiling point, and has been purified by distillation under a reduced pressure, the boiling point at this pressure is published, and in such cases the value of the pressure is usually given. Commonly, to promote quiet boiling, a fine stream of air enters the boiling liquid through a capillary. Examination of the literature shows conclusively, however, that boiling points determined in this way are utterly untrustworthy.

This was clearly exhibited, for example, in connection with the controversy ${ }^{1}$ over the question of whether such a boiling point was identical with the temperature at which the substance exercised a vapor pressure equal to that used in the distillation. Employing a vacuum distillation apparatus of the standard type, but more carefully constructed than the forms commonly used, G. W. A. Kahibaum² found the boiling points to be sometimes higher and sometimes lower. The differences were, indeed, finally demonstrated to be in part due to the fact that the vapor pressure observations which he chose for comparison were inaccurate. ${ }^{3}$ In at least one conspicuous case (butyric acid), also, the material was very impure. ${ }^{4}$ But the greater part of the differences was due simply to the form of this particular apparatus, which was never devised for obtaining exact boilingpoint-pressure readings. The original, and still, practically, the only purpose of the apparatus is to secure efficient purification by fractionation in vacuo. Any form which will achieve this end may be used, and is used.

To illustrate the striking differences between boiling points in a distillation apparatus and the true boiling points under various pressures, as determined in an apparatus especially devised for this purpose, a few

${ }^{1}$ List of references, Ostwald, Handb., I, 308, to which add $Z$. physik. Chem., 7, 438 , and $Z$. physik. Chem., 6, 594 .

${ }^{2}$ Ber., 16, 2476.

${ }^{3}$ Ramsay and Young, Ibid., I9, 2114.

4 Bannow, Ibid., I9, $255^{2}$. 
typical values are given below. In the columns headed $\mathrm{K}$ appear Kahlbaum' $\mathrm{s}^{1}$ boiling points. The substances, in these instances, could not have been seriously impure. Under $R \& Y$ and $Y$ are given the boiling points as ascertained by Ramsay and Young and by Young, respectively, and these results are confirmed by other published data.

\begin{tabular}{|c|c|c|c|c|c|c|c|c|c|c|}
\hline \multirow{2}{*}{$\begin{array}{l}\text { Pres. } \\
\text { sures. } \\
\text { man. }\end{array}$} & \multicolumn{2}{|c|}{ Benzere. } & \multicolumn{2}{|c|}{ Ethyl alcohol } & \multicolumn{2}{|c|}{ Bronobenzene. } & \multicolumn{2}{|c|}{ Aniline. } & \multicolumn{2}{|c|}{ Quinoline. } \\
\hline & $\mathrm{K}$. & $\mathrm{R} \& \mathrm{Y} \mathrm{I}^{2}$ & $\mathrm{k}$. & $R \& Y^{3}$ & $\mathrm{~K}$. & $\mathrm{R} \& \mathrm{Y}$, & $\mathrm{K}$. & $R \& Y .^{4}$ & K. & $y$ \\
\hline $5 \ldots \ldots$ & -0.6 & $\cdots$ & +1.5 & $\cdots$ & 29.8 & 28.5 & $65 \cdot 5$ & $\cdots$ & $97 \cdot 2$ & $89 \cdot 5$ \\
\hline Io..... & $+1 \cdot 3$ & . & 6.5 & -2.85 & $4 \mathrm{I} \cdot 5$ & 40 & 72.7 & $\ldots$ & 106.6 & 104 \\
\hline $15 \ldots \ldots$ & $3 \cdot 3$ & -10 & $9 \cdot 5$ & +2.80 & 49.6 & $47 \cdot 5$ & 78.3 & . & I 12.6 & 113 \\
\hline $20 \ldots \ldots$ & $5 \cdot 1$ & -5 & 12.4 & 7.35 & 55.8 & $53 \cdot 5$ & 83.0 & $8 \mathrm{r} \cdot 5$ & I I 8.0 & $1 \geq 0$ \\
\hline $25 \ldots \ldots$ & 6.4 & $-I_{1}$ & 14.4 & 10.75 & $60 \cdot x$ & 58 & 87.2 & 86 & 121.9 & 125 \\
\hline $50 \ldots \ldots$ & I 3.8 & $+\sqrt{2} 2$ & 23.5 & 22.15 & 70.7 & $73 \cdot 5$ & 100.9 & 102 & 136.5 & 142 \\
\hline $75 \ldots \ldots$ & 20.1 & +20.5 & 29.0 & 29.20 & 77.3 & 83 & 108.2 & I 12.5 & 144.8 & 154 \\
\hline
\end{tabular}

The especial unfitness of the distillation apparatus at low pressures, where the temperature is below that of the room, is shown particularly in the cases of alcohol and benzene. Here, heat reaches the thermometer by radiation faster than it can be removed by a vapor of low heat capacity, and the temperatures are all much too high. Kahlbaum ${ }^{6}$ states that wrapping cotton round the bulb, whether this cotton is previously moistened with the substance or not, does not, in these cases, bring about better correspondence of the results.

Quite recently, Von Rechenberg ${ }^{7}$ has called attention to another error due to the fact that the large amount of vapor passing through the distillation apparatus gives a steep pressure gradient between the flask and the pump. When the manometer is distant from the flask, the observed pressure may be as much as $\mathrm{I} 2 \mathrm{~mm}$. below that existing in the flask. When air is admitted freely through a capillary to prevent "bumping," the steepness of this gradient is higher than it would otherwise be.

It seems, therefore, to be desirable that the boiling points (and corresponding pressures) of substances isolated by vacuum distillation should always be determined by a measurement made especially for the purpose. The submerged bulblet method described above furnishes a simple apparatus, and gives results of the requisite degree of accuracy. It is free from the eiror due to the air entering through the capillary. This method

${ }^{1} \mathrm{Ber} ., 17,1259$.

${ }^{2} J$. Chem. Soc., 55, 50I-3.

${ }^{3}$ Ber, $18,2856$.

${ }^{4} J$. Chem. Soc., 47, 649 .

${ }^{5}$ Ibid., 55,485 .

${ }^{6}$ Ber, I9, 947 .

${ }^{7} J$. prakt. Chem., 79, 475. For further discussion of this subject see Kraffts, Ibid., 2, 80, 242 (I909); Hansen, Ibid., 80, 449; Kraft, Ibid., 80, 469; and the reply of von Rechenberg, Ibid., 80, 547. Also Siepermann, Ibit., 81, I9o; and Hansen, Ibid., $81,282$. 
involves in reality a distillation in vacuo, but the extremely small amount of actual vapor transference occuring completely obviates the source of error noted by Von Rechenberg. The method avoids the error at low temperatures due to superheating of the thermometer by radiation, as the latter is immersed in a bath liquid of great heat capacity. It eliminates also, for the same reason, all the variability in the conditions, and therefore in the results, to which, as we have seen, ${ }^{1}$ the distilling flask method is liable.

For data which are to be published, ready comparability would be secured by choosing a list of predetermined pressures, such as 5, IO, $20,50,75$, I00, $200 \mathrm{~mm}$., etc., up to $760 \mathrm{~mm}$., the particular pressures being selected from this list with reference to the stability of the substance. The simplest way to accomplish this is to make several vaporpressure readings in the desired region, to prepare a temperature-pressure curve from the data, and to read off the temperature at the exact pressures selected.

Reduction of Boiling Points to $760 \mathrm{~mm}$. by Calculation.-It does not seem to be widely known that the observed boiling point at existing atmospheric pressure may be reduced to the value at $760 \mathrm{~mm}$. by calculation alone, and usually without serious error. A rule given by Landolt, ${ }^{2}$ which appears to be the only one that is familiar, is to the effect that the boiling point changes $0.043^{\circ}$ for each mm., or, what is the same thing, $I^{\circ}$ for every $23.3 \mathrm{~mm}$. Now the following changes in pressure for $\mathrm{I}^{\circ}$ at the boiling point show this statement to be too inexact for practical use: Benzene, $24 \mathrm{~mm}$; ether, $27 \mathrm{~mm}$; alcohol, $30.3 \mathrm{~mm}$.; naphthalene, $17 \mathrm{~mm}$.; mercury, I3.6 mm.; water, $27.2 \mathrm{~mm}$. Landolt's rule in reality overlooks the fact that the change in pressure per $\mathrm{I}^{\circ}$ is not constant, but varies inversely with the boiling point on the absolute scale. The following rule, based on the Clausius-Clapeyron law, and identical with, but simpler in form than that of Young, ${ }^{3}$ gives results of accuracy sufficient for many purposes: Divide 8500 by the boiling point on the absolute scale (observed at about one atmospheric pressure), and the quotient is the change in pressure (in $\mathrm{mm}$.) for $I^{\circ}$ change in boiling point.

The constant varies, changing by about I per cent. for every $10 \mathrm{~mm}$. below or above 760 . The above value $(8500)$ can be used, therefore, only for observed boiling points near to $760 \mathrm{~mm}$. This value applies to most substances, but for alcohols, acids, water, and other substances containing the hydroxyl group the value I0200 must be used instead. The following data illustrate the degree of approximation attained by the use of this rule:

'See first paper, This Journal, 32, 897 .

2 Ann. (Liebig), Suppl, 6, 175.

${ }^{3} \mathrm{~J}$. Chem. Soc., $8 \mathrm{x}, 777$. The number 8500 is the reciprocal of Young's constant, c. 


\begin{tabular}{|c|c|c|c|c|}
\hline Benzene. . . . . . . . . & $\begin{array}{c}\text { B.op. C. } \\
80^{\circ}\end{array}$ & $\begin{array}{c}\text { B.-p. abs. } \\
353^{\circ}\end{array}$ & $\begin{array}{c}\text { v. p, change. } \\
\text { obsd. mm. } \\
24\end{array}$ & $\begin{array}{c}\text { V-p. change } \\
\text { calc. mm. } \\
24.1\end{array}$ \\
\hline Naphthalene............ & 218 & $49 \mathrm{I}$ & 17 & $17 \cdot 3$ \\
\hline Chloroform............. & 62 & 335 & $25 \cdot 2$ & $25 \cdot 4$ \\
\hline Carbon distlphide......... & 46 & 319 & $24 \cdot 7$ & 26.6 \\
\hline Aniline $\ldots \ldots \ldots \ldots \ldots \ldots$ & 184 & 457 & $19 \cdot 5$ & 18.6 \\
\hline Methyl acetate.......... & $57 \cdot 5$ & 330.5 & 26.8 & $25 \cdot 7$ \\
\hline Methyl formate......... & $32 \cdot 3$ & $305 \cdot 3$ & 28.8 & 27.8 \\
\hline Amyl $n$-butyrate........ & $\mathrm{I} 78.6$ & 451.6 & 19 & I8.8 \\
\hline Ether $\ldots \ldots \ldots \ldots \ldots \ldots$ & 34.6 & 307.6 & 27 & 27.6 \\
\hline Mercury............. & 357 & 630 & 13.6 & $13 \cdot 5$ \\
\hline Sulphur. . . . . . . . . . & 445 & 718 & 12.2 & II. 8 \\
\hline 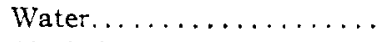 & IOO & 373 & 27.2 & $27 \cdot 3^{1}$ \\
\hline Alcohol. ............... & 78.4 & 35 I. 4 & 30.3 & $28.9^{1}$ \\
\hline Acetic acid $\ldots \ldots \ldots \ldots \ldots$ & 119 & 392 & 24 & $26.0^{3}$ \\
\hline
\end{tabular}

[Contributions from the Research Laboratory of Physical Chemistry of the Massachusetts Institute of Technology, No. 52.]

\section{THE CONDUCTANCE AND IONIZATION OF POTASSIUM TRI-IODIDE, AND THE EQUILIBRIUM BETWEEN IODINE, IODIDE, AND POLYIODIDES IN AQUEOUS SOLUTION.}

By W. C. Bray and G. M. J. Mackay.

Received June I3, igro.

This investigation was undertaken in order to determine the equivalent conductance of the tri-iodide ion, $\mathrm{I}_{3}^{-}$; for a knowledge of this quantity is needed in the study of the equilibrium between iodine, iodide, and polyiodides in aqueous solution. Our own experimental work deals only with dilute solutions; but so much experimental evidence relating to this equilibrium in more concentrated solutions is available that it has seemed worth while to consider the results of several of these investigations from a single point of view. Accordingly, after presenting our own results, we have attempted to calculate the proportion of iodide, tri-iodide, and higher polyiodide present in a normal KI solution saturated with iodine.

The only careful determination of the conductance of tri-iodide ion, $A_{\mathrm{I} 3}$, is that of Burgess and Chapman, ${ }^{2}$ who calculated, from transference experiments, that $A_{\mathrm{I} 3} / A_{\mathrm{I}}=0.566$. If we accept the value $A_{\mathrm{I}}=76.5$ at $25^{\circ}$, as given below, then $A_{I_{3}}$ is found to be 42.5 . We have recalculated these results ${ }^{3}$ and have found the same mean value for $A_{I_{3}}$, although

1 Constant here rozoo, for the others 8500 .

2 Burgess and Chapman, J. Chem. Soc., 85, 1305 (1904).

3 The share of transport of tri-iodide ion, $C_{\mathrm{I}_{3}} \times A_{\mathrm{I}_{3}} /\left(C_{\mathrm{I}_{3}} \times A_{\mathrm{I}_{3}}+C_{\mathrm{I}^{-}} \times A_{\mathrm{I}}+C_{\mathrm{K}}+\times A_{\mathrm{K}}\right)$ equals $\frac{1}{2}(B / A-\mathrm{I})$ and may be obtained directly from the values of $B / A$ given by these authors in the table on page I3 $_{3}$. The concentration ratio $C_{I^{-}} / C_{I_{8}}$ is given as $C_{2} / C_{1}$ in the tables on page ${ }_{13} 09$, the degrees of ionization of $\mathrm{KI}$ and $\mathrm{KI}_{3}$ being assumed equal. 